of the surface of the earth which determines our standard time. I find it difficult to believe that there can be irregular variations in the angular velocity of the earth as a whole; but it seems less difficult if the variations are merely superficial, due to the crust sliding non-uniformly on the interior. I have even entertained the wild idea that the motion of the magnetic poles might be due to this cause ; the magnetism being constant in the interior but with the axis emerging at changing points of the crust as the crust slips over the inner magnet. Unfortunately, so little seems to be known about the motion of the magnetic poles that I have not even been able to make out whether the motion is from west to east as this theory definitely requires.

What interests the geologist more nearly is that the brake is applied only at certain areas on the surface, so that there would be a tendency to crumple the crust more particularly to the west of these areas. It is unfortunate that shallow seas are necessarily the least permanent features of the earth; otherwise I would have asked whether the geologists had evidence of special crumpling in such areas.

I have regarded the crust as fairly mobile from east to west. I suppose the geologists would also like it mobile from north to south in order to have glacial periods in those portions which are now near the equator. It is not possible to hold out much encouragement for such an idea, because we cannot imagine any force acting from north to south. Still if the crust, which is being urged by the east-west force of tidal friction, is resisted by obstacles it may be deflected, finding that say a south-west track offers less resistance. In a long enough time almost any displacement may have happened, granting my hypothesis that the connexion of the crust to the interior is reasonably plastic. So I cannot forbid this possible interpretation of glacial periods in the earlier geological times.

I am sure that it will not be supposed that, in presenting the astronomical side of these questions which belong both to geology and astronomy, I have any intention of laying down the law. The time has gone by when the physicist prescribed dictatorially what theories the geologist might be permitted to consider. You have your own clues to follow out to elucidate these problems, and your clues may be better than ours for leading towards the truth. We both recognise that we are adventuring in regions of extreme uncertainty where future discoveries will probably lead to various modifications of ideas. Where, as in the new views of the age of the earth, physics, biology, geology, astronomy, all seem to be leading in the same direction, and producing evidence for a greatly extended time-scalc, we may feel more confidence that a permanent advance is being made. Where our clues seem to be opposed, it is not for one of us to dictate to the other, but to accept with thankfulness the warning from a neighbouring science that all may not be so certain and straightforward as our own one-sided view seemed to indicate.

\title{
Nature and Reproduction of Speech Sounds. ${ }^{1}$
}

\section{By Sir Richard Paget, Bart.}

$A^{L L}$ the characteristics of English speech-the $A$ vowels and diphthongs and consonant soundscan be produced-as breathed or whispered speechwithout using the larynx at all; so that in the use of the English language (at least) it may be said that the larynx is not an essential organ of speech. The function of the larynx is to give carrying power and inflexion to speech, and melody to song-it has nothing to do with the essential characteristics of speech.

If any one with a normal "ear for music" will whisper the words "Noah's rather at sea "-thinking of the sounds rather than of the sense-they will hear

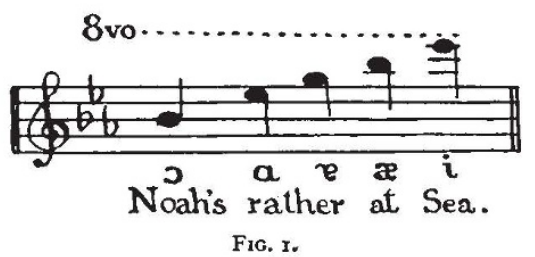

an ascending arpeggio something like the phrase shown in Fig. I. The exact notes heard in each case will depend on how the individual person pronounces the vowel sounds in question.

These whispered or breathed notes are formed, as is well known, by the resonance of the cavity of the mouth, and they are varied for each different vowel

\footnotetext{
2 Substance of a lecture delivered at University College, University of London, on October 18.
}

sound by altering the size of the cavity and the opening of the mouth, mainly through the operation of the tongue and lips. With many of the vowel sounds, namely, i (eat), ei (hay), e (men), $\mathfrak{x}$ (hat), o (not), and in some types of a (calm), two simultaneous resonant notes have been heard by many investigators, but the remaining principal vowel sounds, $\boldsymbol{\supset}$ (all), ou (no), and $\mathbf{u}$ (who), have been generally supposed to be characterised by a single resonance.

Some observations made by me at the beginning of this year, using my own breathed vowel sounds, indicated that in every case the mouth-or rather the oral cavity as a whole, from the larynx to the lipsactually gives two simultaneous resonances for each vowel sound. It appeared that these pairs of resonant notes are not fixed in pitch for any one vowel sound, but might vary over three or four semitones-and sometimes even more-without a very appreciable change in the character of the vowel.

The resonances heard in the use of my own voice are set out in the accompanying chart, in which the vertical scale represents semitones of the equal temperament scale, and the vowel sounds are represented in the notation of the International Phonetic Association (Fig. 2).

It will be seen that $\mathbf{i}$ (eat), I (it), ei (hay), e (men), $\boldsymbol{\gtrless}$ (hat), $\boldsymbol{e}$ (earth), ə (sofa), $\boldsymbol{\Lambda}$ (up), and a (calm) form very nearly a converging series-the upper resonances falling by steps of I to 3 semitones, while the lower resonances are more active and take larger jumps- 
not all in the same direction. From a (calm) onward the resonances go down, as it were, hand-in-hand, keeping an equal distance of about 8 semitones apart; and it is possible, owing to this fact, that they have not been generally recognised as separate resonances.

The double resonance of the oral cavity when forming the vowel sound $\mathbf{u}$ (who) may be demonstrated by the clapping method (see Nature, March I6, vol. I09, p. $34 \mathrm{I})$; also the possibility of varying both resonances independently at the same time. Similarly, the independence of the larynx note and the front resonance may be illustrated by simultaneously humming and whistling a convergent scale.

Having identified the various resonances on which

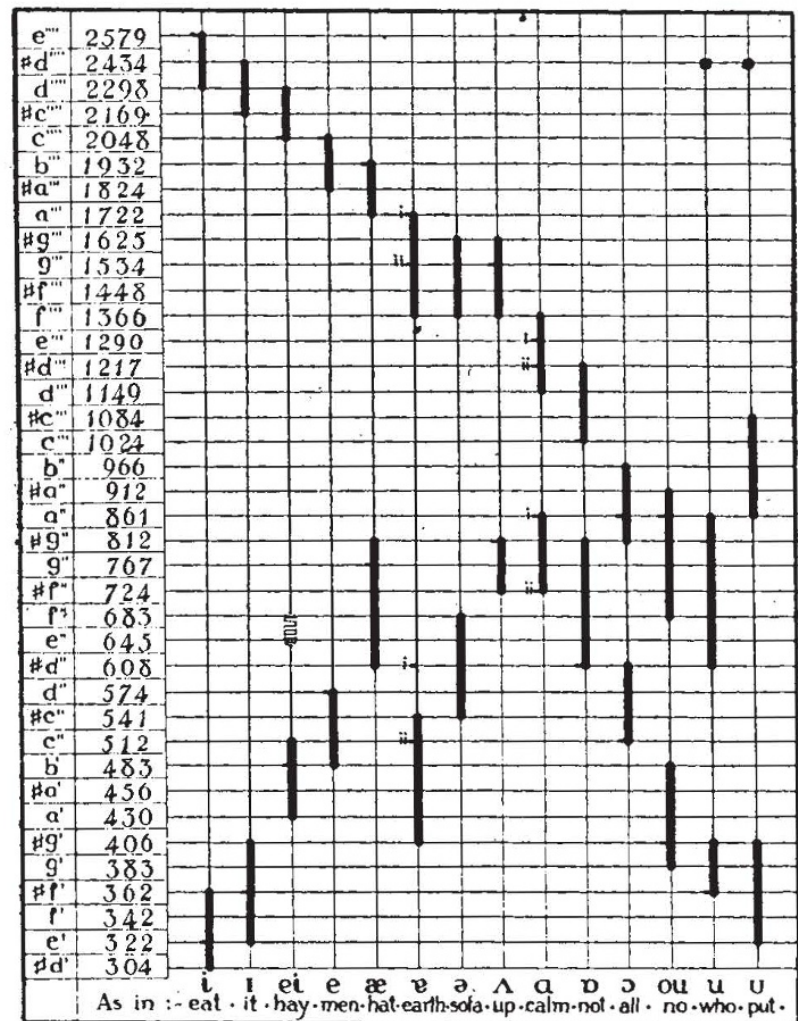

FIG. 2.- Vowel resonance chart. The horizontal dashes on the thick vertical lines denote the actual resonances of the models; the numerals $i$, ii denot successive models of the same vowel.

the production of the breathed vowels appeared to depend, the attempt was made to reproduce these vowel sounds by constructing some form of resonator which had resonances identical with those of the human mouth when a stream of air was blown through it. It seemed reasonable to expect that, if this could be done, the breathed vowel sounds would be reproduced. Models in plasticine were therefore made, the internal form of which very roughly imitated that of the human mouth and throat, except that the back portion corresponding to the pharynx was, for convenience, shortened and made more bulbous.

With this and similar models a number of experiments were made to test the effects of various alterations of the internal form-such as are actually made in the human mouth by the movement of the tongue, lips, etc.-and to discover the rules for tuning the instru- ment. An artificial larynx was made of a rubber strip lying across a flattened air passage-on the principle of the reed instrument which boys make with a blade of grass held between their two thumbs. When this reed or larynx was fitted to the back orifice of the model and blown, the model gave a voiced vowel.

The rules for tuning these models may be shortly summarised as follows: Enlarging the mouth generally raises both resonances. Increasing the projection of the lips or reducing the size of the mouth lowers both resonances. Raising the front of the tongue upwards or forwards raises the upper resonance but lowers the lower resonance. Pressing the back portion of the tongue backwards-so as to reduce the capacity of the back cavity corresponding to the human pharynx and to prolong the passage between the front and back cavities of the mouth-raises the lower resonance but lowers the upper resonance.

The experiments in tuning the plasticine cavities eventually made it clear that the human mouth, when making vowel sounds, always acts as two separate "Helmholtz" resonators connected in series-one behind the other-the back resonator being formed by the pharynx, the back of the tongue, and soft palate; the front resonator being formed by the front of the tongue, the hard palate, and lips; and the passage between the two resonators being formed by a hump in the middle of the tongue which approaches the roof of the mouth. By humping the tongue in different positions-forward or backward-the relative sizes of the front and back resonators can be altered at will, while the tuning can further be modified over a wide range by varying the opening of the mouth.

The resonant note of a cavity with an orifice to the open air depends, as is well known, on the relation between the volume of the cavity and the size of its orifices. The larger the cavity the lower the note; the larger the orifice the higher the note. With a resonant cavity having a neck-such as the neck of a bottle - the resonant pitch also depends on the length of the neck, being lower as the neck is made longer, and higher as the neck is shortened.

It follows from this that when two such resonant cavities are joined together, each one becomes, as it were, a neck to the other, and therefore influences its pitch. The effect is always to lower more or less the resonance of the neighbouring resonator according to the relation of the relative sizes of the two, and of the relative sizes of the connecting opening between the resonators and the opening to the air of the front resonator. The pitch of the resonators was ascertained by tapping them and listening to the resonant notes, or by blowing across the open mouth.

Each of the plasticine models (Fig. 3) made on this principle gives two resonances corresponding to a separate vowel sound. When the various models are blown in succession, first by mouth and afterwards for $\boldsymbol{e}$ (earth) and $\boldsymbol{J}$ (all) by bellows, the vowel characters are made more recognisable by covering and uncovering the mouth of the model by hand during blowing, so as to give an associated consonant ( $m$ or $w)$. It was thus demonstrated that the vowel sound remains appreciably constant however much the pitch of the laryn $x$ note is altered by varying the air pressure.

Instead of putting the two resonators in series, as 
already described, they may be placed in parallelside by side-with a single larynx having a forked or bifurcated passage to communicate with each of them. Two models made on this principle--one tuned to give $\mathrm{i}$ (eat) $\$ \mathrm{~d}^{\prime \prime \prime \prime} 2434$ and $\mathrm{f}^{\prime} 342$ and the other to give $\boldsymbol{\Lambda}$ (up) $\mathrm{g}^{\prime \prime \prime}{ }_{5} 54$ and $\sharp \mathrm{g}^{\prime \prime} 8 \mathrm{r}_{2}$-when blown emit vowel sounds practically the same as those given by the corresponding resonators in series with a single mouth.

Certain vowel sounds can be produced by a single cylindrical or ovoid resonator. An egg-shaped plasticine resonator, when blown through by means of a small hole at the back, gave three resonances-c" ${ }^{\prime \prime} \mathrm{r}_{2}$, $\mathrm{g}^{\prime \prime \prime}{ }_{534}$, and $\mathrm{c}^{\prime \prime \prime \prime} 2048$, and a vowel sound intermediate between $\mathrm{e}$ (men) and $\mathbf{e}$ (earth).

Double resonances may also be obtained from a cylindrical resonator closed at one end and blown through a small orifice in the closed end. A reed-actuated cylindrical resonator of variable length (lent by Prof. D. Jones) gave a series of vowel-like sounds, and a plasticine cylindrical resonator gave $\Delta$ (up) with resonances $\$ \mathrm{gg}^{\prime \prime \prime}{ }^{1625}$ and $\sharp \mathrm{g}^{\prime \prime} 8 \mathrm{I} 2$.

These cases of double resonances produced by a single resonator are interesting as affording a possible explanation of Helmholtz's statement, that he had obtained certain vowel sounds by the use of a single resonator.

The reproduction of the various consonants appears to depend on exactly the same principles, namely, the combination of separate resonators (sometimes more than two), and it has been found possible to reproduce all the English consonant sounds also in this way. The principal difference is that, whereas with the vowels (other than the diphthongs) the resonances are more or less fixed during the voicing of each vowel, with most of the consonants the resonances are rapidly changing, and the consonant sound depends to a large extent on the rate of change.

To summarise these experiments and conclusions: We have seen that each of the English vowel sounds, when whispered or breathed, appears to consist of two musical notes due to the air current from the lungs blowing through the cavity of the mouth and throat. The cavity as a whole is divided up by the tongue into two resonating cavities-one behind the othereach of which produces its characteristic note.

When, instead of passing a steady current of breath through these resonators, we pass a current of air which has previously been set in vibration by the action of the larynx, the sound of the larynx note is coloured by the two resonators respectively and acquires the character which we recognise as voiced vowel sound.

The two resonances which characterise each of the different vowel sounds are not absolutely fixed in pitch for each vowel sound but may vary over several semitones; the tuning of the resonances is performed, in the mouth, mainly by the action of the tongue and lips, and is quite independent of the vibrations of the larynx.

In models, the double resonance of the human mouth can be reproduced by pairs of Helmholtz

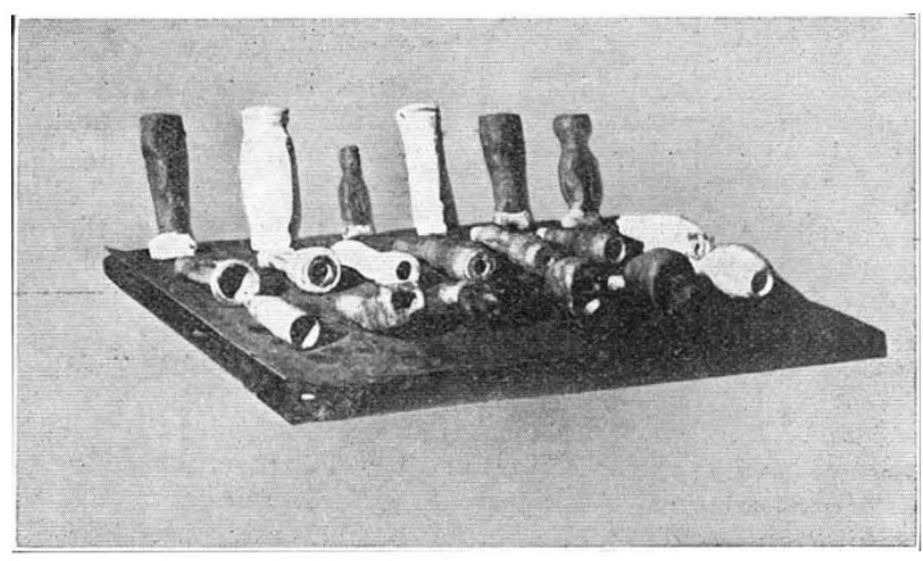

Fig. 3.-Plasticine resonators. resonators joined together in series (making proper allowance for the reaction of each resonator on the resonating pitch one of the other) or by placing the resonators in parallel, side by side, so as to produce a double-mouthed model. When the resonators are driven tandem, the leader and wheeler may be counterchanged-so that, for example, the lower resonance is given by the front resonator instead of by the back, and vice versa.

It follows that it should be possible to write down any vowel sound in musical notation, and to reproduce it by means of a suitable instrument designed to give any required pair of resonances, either in series or in parallel. It also follows that every one who can recognise vowel sounds must have a perfect ear for music, and an almost absolute sense of musical pitch.

\section{Obituary.}

\section{L. WRAGGE.}

$\mathrm{BY}$ the recent death of $\mathrm{Mr}$. Clement L. Wragge, formerly head of the Weather Bureau at Brisbane, at Auckland, New Zealand, meteorology has lost an enthusiastic worker. Mr. Wragge was born at Stourbridge on September I8, I852, and was educated at Uttoxeter Grammar School. After a short period of service in the Surveyor-General's department at Adelaide, he returned to England, where he founded several meteorological stations in North Staffordshire.
When the Scottish Meteorological Society wished to establish a meteorological observatory on Ben Nevis at 4400 feet above sea level, they were fortunate in securing the services of Mr. Wragge, who during the summers of 1881 and 1882 daily ascended the mountain and took regular observations. The Scottish Meteorological Society, in an appeal for public funds to found a permanent observatory on Ben Nevis, referred to " the observations made by Mr. Wragge with such skill, endurance, and enthusiasm during the last two summers on Ben Nevis." That very considerable endurance was 